\title{
Block Mode Study: Opportunities and Challenges for a New Generation of Learners in an Australian University
}

\author{
Gayani Samarawickrema and Kaye Cleary \\ Victoria University, Australia
}

\begin{abstract}
This article is an update on a university-wide overhaul of its pedagogy, curriculum and delivery to support the expanding non-traditional, new generation learners while enhancing opportunity and success for traditional learners. The Block Model developed by Victoria University (VU), Australia for its undergraduate cohort, was a bold response to support all students including its high proportion of First-in-family (FiF), low socio-economic status (LSES), and non-English-speaking background (NESB) students. In this radical new hybrid Block model, students study one unit/subject at a time over four weeks. The article reports on preliminary results after two years of implementing the VU Block Model. While both traditional and new-generation cohorts significantly improved their performance, there was a higher improvement in the pass rates of LSES, NESB and FiF students, compared to the improvements in the traditional cohorts of students. These initial results confirm the value of the institution-wide strategy to expand opportunity and enhance success for all.
\end{abstract}

Keywords: Block mode; new generation learners; opportunity and success.

\section{Background}

This article is a sequel to a previously published Feature Practice Report titled Re-building the first year experience, one block at a time (McCluskey et al., 2019) and serves to update the reader on the outcomes of the initiative based on two years of data. In that practice report the authors, described a university-wide transition experience to service a new generation of learners stimulated by the Dawkins and Bradley reform agendas to promote greater equity in Australian higher education. These reforms have resulted in increased participation and broader student diversity (Brett \& Harvey, 2017) so the sector now includes more First-in-family (FiF), low socio-economic status (LSES), and non-English-speaking background (NESB) students. Devlin and McKay (2011) observed that typically, LSES students juggle work and family responsibilities, are time-poor and are under considerable economic pressure to prioritise work over study. They explained that many of these students experience financial distress and are up to three times as likely to defer study. Similarly, FiF students experience difficulties transitioning into university with little family support to overcome their educational struggles. These students are challenged by feelings of loneliness and isolation amplified by the lack of familiarity with expected behaviour protocols to operate in a higher education setting (O'Shea, 2016). Correspondingly challenged are students who lack English language competence. Murray (2010) confirms that both NESB and English-speaking background (ESB) students who lack language competency feel anxious, frustrated, and demotivated to engage with the learning process. These vulnerable student cohorts, the core of a new generation of learners, are at risk of withdrawing from study as they face more hurdles than their traditional counterparts (Devlin \& O'Shea, 2012). 
Of all the Australian universities, Victoria University (VU) has the highest proportion of these students making its cohort among the most diverse in this sector (Victoria University, 2012). Approximately half of VU's students come from the inner West of Melbourne, home to large numbers of new immigrants including many of whom are the first in their family to enter university, while others may hold a university qualification from another country. For many, English is not their first language. Through a series of in-depth, theoretically informed case studies and discussions, Funston et al. (2014) explored issues related to transition and retention and the particular challenges experienced by these VU students. Over decades many universities targeted similar students from economically and educationally disadvantaged backgrounds offering innovative strategies to support them, resulting in a range of ad hoc specialist services (Thomas, 2014). Funston (2014) took a case study approach to understand VU's non-traditional student cohort including their possible causes for attrition, disorientation, and extreme loneliness while Funston et al. (2014) described VU's numerous multi-pronged strategies targeted to support the various equity groups to shift their persistent under-representation in higher education. This work formed a useful background, considering its direct contextual relevance.

Although access to higher education has improved, the achievement gaps for instance between high- and LSES students, or between NESB and ESB are still significant. Tinto (2008) argued that "access without effective support is not opportunity" and what is required is substantial restructuring of the student experience, especially for those who are academically under-prepared when entering university (Tinto, 2008, para 24). This has become VU's challenge. This article outlines a radical institutionwide overhaul and reports on how VU embraced the notions of support and opportunity to pathway its expanding non-traditional new generation of learners from disadvantaged backgrounds, to success. This evidence-based update from two years of data complements the report by McCluskey et al. (2019) and builds on the evidence reported by McCluskey et al. (2020) after the first year of the Block Model to demonstrate how the strategies employed facilitated 'success' for all students.

\section{Intensive Modes of Teaching and the VU Block}

Modularised programs, popular in $20^{\text {th }}$ century UK higher education (Fry et al., 2002), as well as in the USA and Australia, lend themselves to intensive modes of delivery such as accelerated, compressed, time-shortened and block modes. Modularisation of learning was in part a response to provide for diverse student groups, and to create curriculum flexibility (French, 2015). In her review of benefits and challenges of modular higher education, French (2015) argued that its flexible study periods allowed greater mobility for students, and increased opportunity for interdisciplinary learning. Modular approaches have been valued for their capability to deliver knowledge in 'bite-sized' pieces structured developmentally as a staged approach to learning (Hodgson \& Spours, 1997). Conversely, French cautioned that this potential can also fragment learning by disaggregating content, and assessing discrete components of learning to the exclusion of integrative learning. Others have also critiqued the intellectual fragmentation of modularisation for its ability to simplify the complexity of the real world (Hall \& Smyth, 2016) by limiting opportunity for discussion, analysis of material and reflection, leading to lowered standards (French, 2015).

As defined by Davis (2006), 'intensive mode delivery' (IMD) are subjects delivered in their entirety in a shortened timeframe, in contrast to the traditional 12-16 week semester. Given integration of knowledge occurs over time, the important relationship between time and learning has been explored since IMD has been systematically implemented. While early results found no significant difference in learning (e.g. economics [Van Scyoc \& Gleason, 1993]), subsequently, drawing on a database of 45,000 observations, Austin and Gustafson (2006) studied the impact of course length on student learning. This extensive study found that there is a significant improvement in learning from taking shorter courses with the benefit peaking at courses lasting four weeks, with improved grades having "the same explanatory power for future performance as those earned during a traditional 16 week semester" (p. 27). In Australia, IMD summer schools and accelerated programs have been offered by universities in a number of disciplines such as postgraduate business and management (Burton \& Nesbit, 2008), undergraduate science (Harvey et al., 2017), second year pharmacology (Karaksha et al., 2013), marketing (Ho \& Polonsky, 2009), law (Ellis \& Sawyer, 2009, Ramsay, 2011) and neuroanatomy (Whillier \& Lystad, 2013), to name a few. The guide by the Australian government Office for Learning and Teaching (OLT) on IMT (Male et al., 2016) advising how to optimise students' experiences when intensive modes are used, is clear acknowledgement of this growing national and international trend.

Building on the effectiveness of these Australian-based IMD programs and similar international successes, and mindful of the contested dimensions of modularisation, VU developed its Block Model in 2017. Until then, no Australian university had implemented an institution-wide overhaul of its pedagogy, curriculum and delivery to support this expanding non-traditional 
new generation of learners. The Block Model developed by VU for its undergraduate cohort was a bold response to address widening participation, and support all students including its customary high proportion of students from diverse backgrounds. This VU Block Model is a hybrid model comprising an on-campus or community-based physical learning environment, and a virtual learning environment. By focusing on VU's vision statement 'University of Opportunity and Success', the model makes a strong institutional commitment to all its learners.

\section{Figure 1}

\section{The VU Block Model}

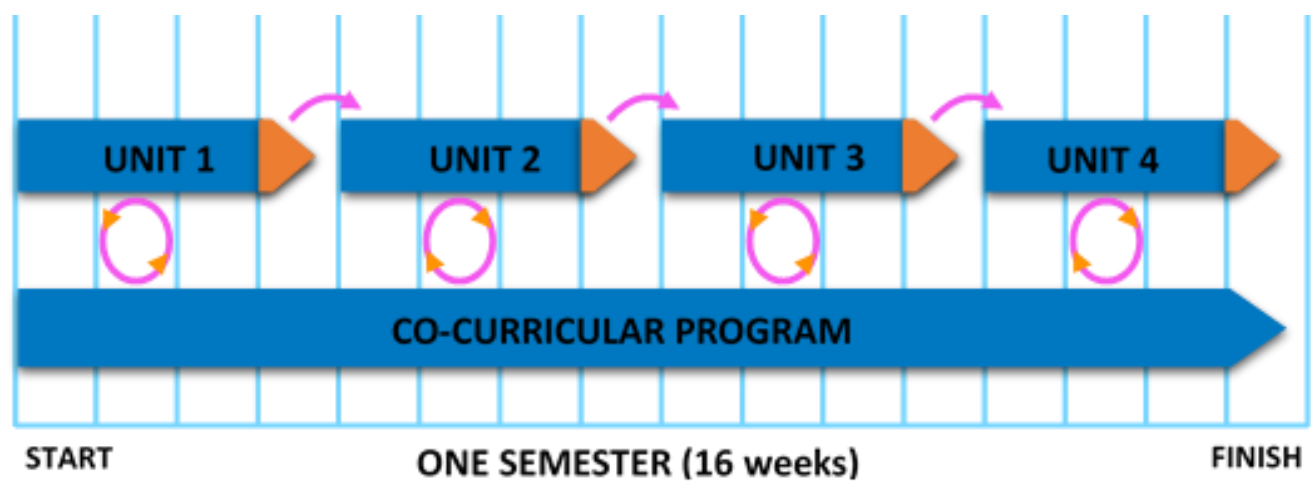

As illustrated in Figure 1, students study one block at a time over four weeks in 11 sessions. Each block includes structured independent learning supported via the learning management system (LMS). The duration of each session is equivalent to the class contact time typical for a week's study of a single unit/subject across a whole semester. This contrasts with concurrently studying four subjects across a single 12-week teaching semester, plus a 4-week examination period. This radical approach is complemented by a co-curricular program through the semester which is designed to enhance opportunity and success (McCluskey et al., 2019).

The VU initiative concentrates on the totality of the student learning experience. With the student at the centre, the focus is to reduce the complexity of study and increase opportunities for success. This is addressed by developing a sense of belonging through small classes and systematically introducing collaborative work. Integral to the strategy is building confidence in capabilities through opportunities for early success via a low-stakes assessment in the first week and developmental or nested assessments to foster depth of knowledge. These purposefully built opportunities deliberately linked to students' success strategies were designed to reduce any sense of disconnect. Such strategies have been endorsed by Walker-Gibbs et al. (2019) in their extensive report to the National Centre for Student Equity in Higher Education (NCSEHE).

In addition, a co-curricular program that explicitly builds academic and employment-related skills runs through each Block across each semester and year level. This co-curricular program does not operate in isolation but is an integrated sustained institutional strategy meaningfully linked to other academic and co-curricular programs on campus. Such programs have been found to enhance student success (Polnariev \& Levy, 2016). For example, in a three-year undergraduate degree, the Year 1 cocurricular program offers 'Study Essentials', in Year 2 'Course Essentials' and in the final year 'Career Essentials', building a scaffolded culture of success. This carefully designed co-curricular program targets all students and guides them to "develop the critical and communicative skills and conceptual repertoires that will enable them to deal with academic tasks" (Devlin \& McKay, 2011, p. 5). This VU co-curricular program is in contrast to assuming that non-traditional students have 'special needs' that require attention outside the curriculum in adjunct programs.

Therefore, the overarching curriculum approach is consistent with the Theory of Possible Selves (Harrison, 2018), focussing on developing capacity for all (O'Shea \& Delahunty, 2018) to avoid a deficit model (Walker, 2008) of this new generation of learners. Through the hybrid Block design, VU is deliberately moving away from a disconnected consideration of specific equity groups to a holistic conceptualisation of a new generation of learners. This parallels the move towards a universal tertiary education, away from individual challenges associated with massification of higher education (Tight, 2019). Based on this 
rationale, the learning design built clear connections to potential future careers, right at the outset, focusing on the student destination rather than the differences at admission to VU. In addition, the learning design clearly embedded constructively aligned learning, assessments, graduate attributes and professional/industry requirements. Minimising information transmission, the design focusses on what students 'do' through active learning and purposefully combines the classroom, LMS and off-site learning, creating the VU hybrid blended learning environment. A team of professional staff partnered with academic staff and carefully designed this hybrid Block approach for each unit/subject based on evidence of previous offers including previous student evaluations of those offers. Together with the academic staff, this team was also responsible for quality assurance, maintaining standards and ensuring that each unit/subject met the national standards and requirements of the related professional body. The Block Model was guided by seven design principles and seven implementation principles (Table 1) drawn from validated pedagogies related to learning and transition (Chickering \& Gamson, 1987, Kift, 2009).

Table 1

The Block Model Design and Implementation Principles to Increase Opportunities for Success

Design principles to increase opportunities for success

(1) Immersive sessions with clear beginnings and conclusions linked to pre-/post-class activities and explicit de-briefings to conclude learning

(2) Variety of learning opportunities and a variety of assessment tasks (to accommodate student diversity and build depth and explore breadth)

(3) Developmental assessments, building in collaboration and feedback

a) Assessments to be completed and marked within 2 working days

b) Clear assessment tasks and rubrics indicating requirements

(4) Knowledge exploration and application, not content transmission (active learning, not lectures)

(5) Opportunities for peer feedback and collaboration (using experiential opportunities and peer learning)

(6) Predictable timetable: typically 3 days per week (enabling students to undertake other responsibilities)

(7) Assessments meet the required Australian Qualification Framework (AQF) standards and any professional body conditions/prerequisites
Implementation principles to increase opportunities for success

(1) Be student-centred, active, and engaging (you are the University - be 'fabulous')

(2) Outline the relevance/connections of units to course and career (show connection with long-term goal, and counter fragmentation of learning)

(3) Provide early ongoing feedback (help students calibrate their performance)

(4) Listen to students - their interests, needs/expectations (modify delivery as relevant)

(5) Include opportunities for self-assessment that leads to personalised and adaptive learning (scaffold learning and assist students to independently recognise personal strengths, weaknesses, and appropriateness of responses to tasks)

(6) Integrate authentic learning practices (be engaging and relevant)

(7) Leverage digital technology as part of the blended learning $\operatorname{mix}$

These VU Block Model design and implementation principles are confirmed by Kuiper et al. (2015) in their work on IMD and compressed courses. Further to their study, they advised focusing on the student cohort and encouraging commitment right at the start, motivating students through clear design and presentation, incorporating scaffolded, well-sequenced assessments and using learning technologies effectively. Scott (2003) argued that students experience intensive courses differently to traditional formats and yield similar or superior results if best practices such as: focused learning; in-depth discussion; emphasis of core concepts; classroom relationships; meaningful assessment; active classroom instruction; good course organisation, are applied. She further stressed the criticality of easy-to-follow, strong unit/subject organisation, particularly because the unit/subject progresses rapidly. She also highlighted the increased learner satisfaction when instructor enthusiasm and strong staff-student relationships are fostered. These pedagogical attributes are embedded in the VU Block Model design and implementation principles in consideration of all learners including the diverse new generation of learners. 
The VU Block Model principles (Table 1) embody inclusive teaching and are now supported through VU's policy framework and culture. The entire pedagogy, including curriculum design, delivery, engagement, assessment, learning support and the learning environment is focused on inclusion in order to maximise opportunities for success. From 2018, all first-year students at VU studied in this mode. This article investigates if the strategies listed in Table 1 had an impact on VU's LSES, FiF and NESB cohorts and specifically whether it enhanced the academic performance of this new generation learners. The next sections of this article report on the results obtained by both the non-traditional new generation of learners and the traditional learners in Block mode study.

\section{Method}

As per VU research data management practices of supporting the research community, institutional data is shared for purposes of planning, publication and reuse. This study therefore drew on available data from the VU Data Insights team as well as an all-encompassing report of results after the first year of the Block delivery offered to the University's Academic Board by Smallridge (2019). Consequently, and since no additional new data was collected, ethical approval to conduct this study was not required.

The study compared the first-year student results in 2017 attained in the conventional semester system with equivalent subjects studied in Block mode in 2018 and 2019 (Table 2). The analysis by the VU Data Insights team comprised the entire first cohort of students in 2018 and the second cohort of students in 2019 who studied one year in the VU Block.

\section{Table 2}

The First-year Student Results and EFTSL

\begin{tabular}{|l|c|c|c|}
\hline & $\begin{array}{c}\text { 2017 Conventional semester } \\
\text { system }\end{array}$ & 2018 VU Block & 2019 VU Block \\
\hline First-year student results & 29739 & 34462 & 34389 \\
\hline $\begin{array}{l}\text { Effective full-time student } \\
\text { load (EFTSL) }\end{array}$ & 3717 & 4307 & 4299 \\
\hline
\end{tabular}

Demographic filters were applied to this data in Table 2 to focus on three specific student groups - NESB, FiF and LSES. The next section elaborates on emergent results and deliberates on pedagogical factors that may have influenced these preliminary outcomes.

\section{Results}

Across VU, the 2018 results were positive indicating a significant improvement in pass-rates. More students passed their units and achieved higher grades in comparison to 2017. Figure 2 is a comparison of results for students from all disciplines studying First Year subjects in 2017, 2018, and 2019. Results are presented from the highest grade 'HD' (High Distinction), to the lowest 'N' (Not yet passed). Results from 2019 consolidates the 2018 trend. 


\section{Figure 2}

Comparison of First-year Student Results and Grade Distribution in 2017, 2018 and 2019

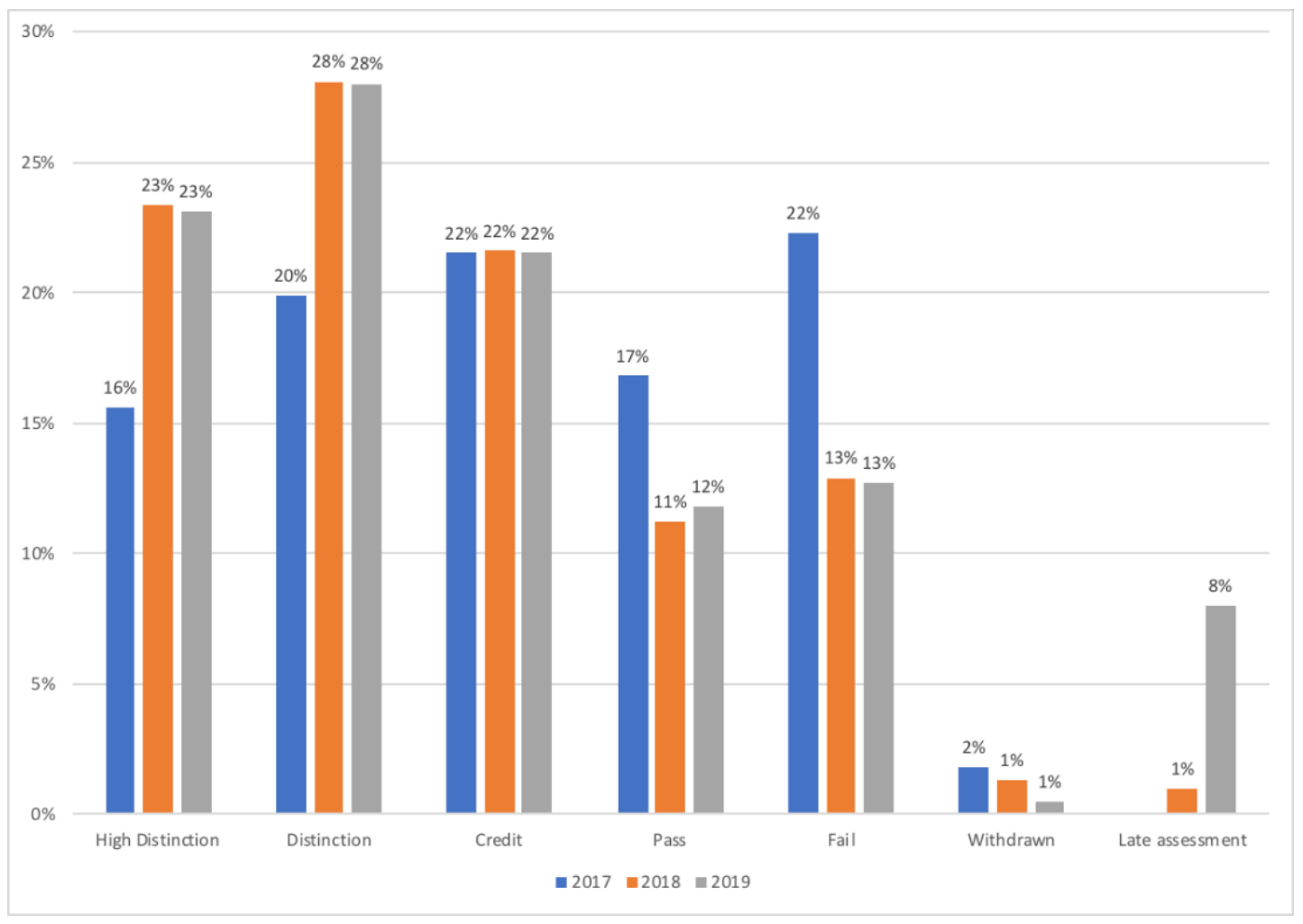

Figure 2 indicates that following the VU Block initiative in 2018, not only have more students passed overall, but more achieved Distinctions (D) and High Distinctions (HD). While the percentage of students obtaining Credits remained stable, those obtaining higher grades (D and HD) increased by $13.4 \%$. Concurrently, those obtaining lower grades (P and $\mathrm{N}$ ) decreased by $13.8 \%$. Figure 2 also indicates that 2019 results consolidate those in 2018 . Clearly, the initiative had addressed some critical impediments to passing. This improvement was plainly reflected among NESB, low SES and FiF students as well.

\section{Non-English-speaking Background}

Table 3

Comparison Between Pass Rate of Non-English-Speaking Background Students and English-Speaking Background Students

\begin{tabular}{|l|l|l|l|l|l|}
\hline \multicolumn{3}{|c}{ Pass rate - NESB } & \multicolumn{2}{c|}{ Pass rate - ESB } \\
\hline 2017 & 2018 & 2019 & 2017 & 2018 & 2019 \\
\hline $67 \%$ & $83 \%$ & $83 \%$ & $76 \%$ & $87 \%$ & $88 \%$ \\
& $(16 \%$ increase $)$ & & & $(11 \%$ increase $)$ & $($ further $1 \%$ increase $)$ \\
\hline
\end{tabular}

The most noticeable improvement was evident in NESB students. Table 3 shows the pass rate of this group improving from $67 \%$ in 2017 to $83 \%$ in 2018. The pass rate of the English-speaking background students also improved considerably, again indicating a positive impact on all students. In 2018 the performance disparity between the two groups narrowed from $11 \%$ in 2017 to $4 \%$ in 2018 . These 2018 pass rates mostly remained steady in 2019 with small improvements among English-speaking background students. 


\section{Low, Medium and High SES}

\section{Table 4}

Comparison of Pass Rates Between Low, Medium and High SES Students

\begin{tabular}{|c|c|c|c|c|c|c|c|c|}
\hline \multicolumn{3}{|c|}{$\begin{array}{l}\text { Pass rate - } \\
\text { Low SES }\end{array}$} & \multicolumn{3}{|c|}{$\begin{array}{c}\text { Pass rate - } \\
\text { Medium SES }\end{array}$} & \multicolumn{3}{|c|}{$\begin{array}{l}\text { Pass rate - } \\
\text { High SES }\end{array}$} \\
\hline 2017 & 2018 & 2019 & 2017 & 2018 & 2019 & 2017 & 2018 & 2019 \\
\hline $67 \%$ & $\begin{array}{l}82 \% \\
(15 \% \\
\text { increase) }\end{array}$ & $\begin{array}{l}85 \% \\
\text { (further } \\
3 \% \\
\text { increase) }\end{array}$ & $73 \%$ & $\begin{array}{l}86 \% \\
(13 \% \\
\text { increase) }\end{array}$ & $86 \%$ & $77 \%$ & $\begin{array}{l}87 \% \\
(10 \% \\
\text { increase) }\end{array}$ & $\begin{array}{l}88 \% \\
\text { (further 1\% } \\
\text { increase) }\end{array}$ \\
\hline
\end{tabular}

Results show improved pass rates of LSES students with similar gains for medium and high SES students. As Table 4 demonstrates, the LSES group recorded the greatest improvement from $67 \%$ to $82 \%$. The improvements have also served to reduce the gap between low and high SES students from 10\% in 2017 to 5\% in 2018 and 3\% in 2019. 2019 also continued to record improved pass rates among both LSES and high SES students.

\section{First-in-Family}

Table 5

Comparison of Pass Rates Between FiF and Non FiF Students

\begin{tabular}{|l|l|l|l|l|l|}
\hline \multicolumn{3}{|c|}{ Pass rate - FiF } & \multicolumn{2}{c|}{ Pass rate - non FiF } \\
\hline 2017 & 2018 & 2019 & 2017 & 2018 & 2019 \\
\hline $71 \%$ & $85 \%$ & $85 \%$ & $76 \%$ & $87 \%$ & $87 \%$ \\
& $(14 \%$ & & $(11 \%$ increase $)$ & \\
\hline & increase $)$ & & & \\
\hline
\end{tabular}

As Table 5 indicates, the pass rate of FiF improved by $14 \%$ between 2017 and 2018 with a rise from $71 \%$ to $85 \%$. Concurrently, an $11 \%$ rise in those not $\mathrm{FiF}$ indicating a clear positive impact on all. The difference between the pass rate of FiF and not FiF decreased in 2018, falling from 5\% to $2 \%$. The results in 2019 were consistent with the gains made in 2018.

\section{Limitations}

A limitation of this study was the use of traditional national framing approaches to equity, treating each student as a group member of an equity group, or not. Had the data used intersectionality approaches proposed by Naylor et al. (2016), a more nuanced insight into disadvantages through connections between FiF, LSES and NESB would have been potentially possible. Another limitation of this study is the consideration of 'success' in terms of results and grades. According to Delahunty and O'Shea (2019), while students value grades, their idea of success extended to less tangible outcomes such as quality of life, happiness and confidence. Exploring these were outside the scope of this study.

Isolating or identifying variables that contributed to the outcomes or the extent to which any given variable was more powerful, and in which disciplines is not yet possible. These may be areas for further student-centred studies.

\section{Discussion}

These preliminary results based on two years of data serve to confirm the appropriateness of supportive pedagogy systematically applied in the institutional curriculum overhaul. 
The many Australian and international experiences related to modular, accelerated, time-shortened, compressed, intensive forms of education provided useful guidance in designing the hybrid VU Block Model. In addition, the strategies adopted by the VU Block Model (Table 1) are underpinned by good instructional design principles and are well known as good practice for effective teaching, learning and assessment. VU Block Model approach systematically and purposefully applied selected good practices with a clear understanding of the context, the particular learner needs and their constraints. These practices incorporated research on supporting the needs of a variety of new generation learners and were applied with the expectation that it would support all learners. For instance, specific focus on the clarity of assessments, their instructions, the way tasks are assessed through straightforward rubrics and explicitly developing assessment literacy strategies are certainly beneficial to all student groups. Learning designs fostering confidence and self-esteem, in turn affects students' overall sense of 'belonging' in higher education. It is therefore difficult to isolate individual factors or strategies that were significant in improving the outcomes for a specific population group in this article without further, more in-depth research. Nonetheless, influencing factors can be conjectured with reference to previously discussed published studies.

For NESB students, the frequent embedded opportunities and activities to develop fluency and confidence may have improved engagement and reduced isolation. Through activities that drew on their formal and functional language knowledge in authentic contexts, both NESB as well as ESB students benefited. The many videos and opportunities for practice in private before attending class may have been useful in building NESB students' negotiation of the local idiom and accent and confidence in using academic language.

The Block learning design systematically integrated a range of pre-class preparation activities and post-class consolidation activities with estimations of time required to complete tasks, thereby maximising time-on-task. This may have helped timepoor LSES students to prioritise out of class activities alongside their other responsibilities such as engagement in paid work or undertaking caring responsibilities. It may have assisted others who needed basic guidance in time management as well.

It is possible that integrating co-curricular programs on study skills, a strategy to 'normalise' student choices about seeking support, particularly helped the FiF students who have not been exposed to tertiary processes and study. Emphasising relationships between concepts in a unit/subject to other subjects and to careers helps counter the potential fragmentation of learning for FiF students who may anticipate that each subject is a stand-alone entity.

We also speculate that the very structure of the Block created a positive learning environment and contributed to some of these outcomes. For instance, the small class-size (capped at 35 students) helped to foster connections with peers, developed a sense of community, breaking down feelings of isolation and nurtured a sense of belonging. The 'relentless welcome' experienced when commencing each Block, encouraged repeated commitment, further promoting engagement with study for all students.

\section{Conclusion}

Our early results indicate that the VU Block Model may be, as Davies suggested, 'an idea whose time has come' (Davis, 2006, p. 14). After the two year of offer, our students' results have shown improvement. The early positive results indicate that the VU Block mode has expanded opportunity and enhanced success for all students. Certainly, for FiF, NESB and LSES groups in our study, VU Block mode learning has been a successful initiative to improve their performance. The institutional changes in response to NESB, LSES and FiF students' challenges are now opportunities for our entire student cohort. Our new generation of learners are no longer part of our retention problem, rather they are our solution going into the future. Nonetheless, the VU Block Model remains a work in progress. While results from the first two years are heartening, these successes must be understood, built upon and streamlined as business-as-usual within the institution.

While academics continue to refine their teaching approaches as they become more familiar teaching in Block mode, all Block units will undergo the regular and systematic university program improvement process. Together these will refine and finetune units and courses to enhance the student experience. It is anticipated that students will become more accustomed with their role and responsibilities in learning in the Block, and leverage its advantages to their benefit. While this process continues, our next advancement would be to integrate student analytics to follow up on the performance of these student groups and their retention using predictive models with context and meaning as suitable to each program. For instance, the predictive model for a program which has a high percentage of FiF and one with a high percentage of NESB students will be different. 
The VU Block Model will further evolve following critical evidence-based judgements made possible on completion of some key longitudinal studies and informed debate. Several institutional research projects and smaller projects investigating the impact and effectiveness of aspects of the VU Block on teaching, student learning and performance across a range of disciplines are underway. These will contribute to the evidence base for ongoing improvement for student achievement at VU. This article focusing on opportunity and success of VU's new generation learners, is one such contribution.

\section{Acknowledgements}

The data for this study was analysed and shared by Victoria University Data Insights team. The 2018 results published in the First Year College Report - Report to Academic Board (Smallridge, 2019) is gratefully acknowledged.

\section{References}

Austin, A. M., \& Gustafson, L. (2006). Impact of course length on student learning. Journal of Economics and Finance Education, 5(1), 26-37.

Brett, M., \& Harvey, A. (2017). Advancing equity in the Australian higher education system. In R. James, S. French, \& P. Kelly (Eds.), Visions for Australian tertiary education (pp. 77-89). Melbourne Centre for the Study of Higher Education,

Burton, S., \& Nesbit, P. L. (2008). Block or traditional? An analysis of student choice of teaching format. Journal of Management and Organization, 14(1), 4-19. https://doi.org/10.1017/S1833367200003448

Chickering, A. W., \& Gamson, Z. F. (1987). Seven principles for good practice in undergraduate education. The Wingspread Journal, 9, 1-10.

Davis, M. (2006). Intensive teaching formats: A review. Issues in Educational Research 16(1), 1-20. http://www.iier.org.au/iier16/davies.html

Delahunty, J., \& O'Shea, S. (2019). "I'm happy, and I'm passing. That's all that matters!": Exploring discourses of university academic success through linguistic analysis. Language and Education, 33(4), 302-321. https://doi.org/10.1080/09500782.2018.1562468

Devlin, M., \& McKay, J. (2011). Inclusive teaching and support of university students from low socioeconomic status backgrounds (Discussion paper). Deakin University.

Devlin, M., \& O'Shea, H. (2012). Effective university teaching: Views of Australian university students from low socioeconomic status backgrounds. Teaching in Higher Education, 17(4), 385-397. https://doi.org/10.1080/13562517.2011.641006

Ellis, B., \& Sawyer, J. (2009). Regional summer schools: Widening learning opportunities through intensive courses. Education in Rural Australia 19(1), 35-62.

French, S. (2015). The benefits and challenges of modular higher education curricula. In Issues and Ideas Paper. Melbourne Centre for the Study of Higher Education. https://melbournecshe.unimelb.edu.au/_data/assets/pdf_file/0006/2774391/Benefits_Challenges_Modular_Higher_Ed_Curricula_SFrench v3-green-2.pdf

Fry, H., Ketteridge, S., \& Marshal, S. (2002). The effective academic: A handbook for enhanced academic practice. Taylor \& Francis.

Funston, A. (2014). Getting to know our students better through a mixed-methods case study of their first-year experiences. In A. Funston, M. Gil \& G. Gilmore (Eds) Strong starts, supported transitions and student success. (pp. 67-104). Cambridge Scholars Publishing.

Funston, A., Gil, M., \& Gilmore, G. (Eds.). (2014). Strong starts, supported transitions and student success. Cambridge Scholars Publishing.

Hall, R., \& Smyth, K. (2016). Dismantling the curriculum in higher education. Open Library of Humanities, 2(1), 1-28. http://dx.doi.org/10.16995/olh.66

Harrison, N. (2018). Using the lens of 'Possible Selves' to explore access to higher education: A new conceptual model for practice, policy and research. Social Sciences, 7(10). https://doi.org/10.3390/socsci7100209

Harvey, M., Power, M. \& Wilson, M. (2017). A review of intensive mode of delivery and science subjects in Australian universities. Journal of Biological Education, 51(3), 315-325. https://doi.org/10.1080/00219266.2016.1217912

Ho, H., \& Polonsky, M. (2009). Exploring Marketing students' attitudes and performance: A comparison of traditional and intensive delivery. Marketing Education Review, 19(3), 41-47. https://doi.org/10.1080/10528008.2009.11489086 
Hodgson, A. \& Spours, K. (1997). Modularization and the 14-19 qualification system In A. Hodgson and K. Spours (Eds.), Dearing and beyond: 14-19 qualifications, frameworks and systems. Routledge. https://doi.org/10.4324/9781315041902

Karaksha, A., Anoopkumar-Dukie, S., Grant, G.D., Davey, A., Nirthanan, S., Arora, D., Hope, D., Bernatis, N., McFarland, A., Hall, S., Haywood, A., Holani, C., Chess-Williams, R., \& Mcdermott, C. (2013). Benefits of intensive mode teaching to improve student performance. 6th International Conference of Education, Research and Innovation (ICERI2013) Proceedings, Saville, Spain.

Kift, S. (2009). Articulating a transition pedagogy to scaffold and to enhance the first year student learning experience in Australian higher education. Australian Learning and Teaching Council. http://transitionpedagogy.com/

Kuiper, A., Solomonides, I., \& Hardy, L. (2015). Time on task in intensive modes of delivery. Distance Education, 36(2), 231-245. https://doi.org/10.1080/01587919.2015.1055058

Male, S., Baillie, C., Hancock, P., Leggoe, J., MacNish, C., Crispen, S., Ranmuthugala, D. \& Alam, F (2016). Intensive mode teaching guide. Office for Learning and Teaching.

https://www.staff.uwa.edu.au/_data/assets/pdf_file/0004/2886052/IMT-Guide-Recommendations-v4b-for-web.pdf

McCluskey, T., Weldon, J., \& Smallridge, A. (2019). Rebuilding the first year experience, one block at a time. Student Success, 10(1), 1-15. https://doi.org/10.5204/ssj.v10i1.1148

McCluskey, T., Smallridge, A., Weldon, J., Loton, D., Samarawickrema, G. \& Cleary, K. (2020). Building on the VU Block foundations: Results from the inaugural first year cohort. In E. Heinrich and R. Bourke (Eds.), Research and Development in Higher Education: Next generation, Higher Education: Challenges, Changes and Opportunities, 42: 61-72. https://www.herdsa.org.au/publications/conference-proceedings/research-and-development-higher-education-nextgeneration-6

Murray, N. L. (2010). Conceptualising the English language needs of first year university students. The International Journal of the First Year in Higher Education, 1(1), 55-64. https://doi.org/10.5204/intjfyhe.v1i1.19

Naylor, R., Coates, H. \& Kelly, P. (2016). From equity to excellence: Reforming Australian's national framework to create new forms of success. In A. Harvey, C. Burnheim \& M. Brett (Eds.), Student equity in Australian higher education: Twenty-five years of a Fair Chance for All (pp. 257-274). Springer.

O'Shea, S. (2016). First-in-family learners and higher education: Negotiating the 'silences' of university transition and participation. HERDSA Review of Higher Education 3. https://www.herdsa.org.au/herdsa-review-higher-education-vol3/5-23

O'Shea, S. \& Delahunty, J. (2018). Getting through the day and still having a smile on my face! How do students define success in the university learning environment? Higher Education Research \& Development, 37(5), 1062-1075. https://doi.org/10.1080/07294360.2018.1463973

Polnariev, B.A., \& Levy, M.A. (2016). Promoting student success via collaboration. In M.A. Levy \& B.A. Polnariev (Eds.), Academic and student affairs in collaboration: Creating a culture of student success. Routledge.

Ramsay, I. (2011). Intensive teaching in law subjects. The Law Teacher, 45(1), 87-100. http://dx.doi.org/10.2139/ssrn.1743865

Scott, P.A. (2003). Attributes of high quality intensive courses. New directions for adult and continuing education, 29-38. Wiley Periodicals, Inc.

Smallridge, A. (2019). First Year College Report - Report to Academic Board. Victoria University, Melbourne.

Thomas, G. (2014). Closing the policy-practice gap for low-SES students in higher education: The pedagogical challenge. Higher Education Research \& Development, 3(4), 807-820. https://doi.org/10.1080/07294360.2013.863846

Tight, M. (2019). Mass higher education and massification. Higher Education Policy, 32, 93-108. https://doi.org/10.1057/s41307-017-0075-3

Tinto, V. (2008). Access without support is not opportunity. Inside Higher Ed, June. https://www.insidehighered.com/views/2008/06/09/access-without-support-not-opportunity

Van Scyoc, L. J., \& Gleason, J. (1993). Traditional or intensive course lengths? A comparison of outcomes in Economics learning. The Journal of Economics Education, 24(1),15-22.

Victoria University (2012). The VU agenda and blueprint for curriculum reform: Capabilities for the future. Victoria University, Australia. https://www.vu.edu.au/sites/default/files/wfg/pdfs/VUAgenda-CurriculumBlueprint-Nov2012.pdf

Walker, M. (2008). Widening participation; widening capability. London Review of Education, 6(3), $267-279$. https://doi.org/10.1080/14748460802489397

Walker-Gibbs, B., Ajjawi, R., Rowe, E., Skourdoumbis, A., Thomas, M. K. E., O’Shea, S., Bennett, S., Fox, B., \& Alsen, P. (2019). Success and failure in higher education on uneven playing fields. Curtin University https://www.ncsehe.edu.au/publications/success-failure-higher-education-uneven-playing-fields/

Whillier, S., \& Lystad, R.P. (2013). Intensive mode delivery of a Neuroanatomy unit: Lower final grades but higher student satisfaction. Anatomical Sciences Education, 6, 286-293. https://doi.org/10.1002/ase.1358 


\section{Please cite this article as:}

Samarawickrema, G., \& Cleary, K. (2021). Block mode study: Opportunities and challenges for a new generation of learners in an Australian university. Student Success, 12(1), 13-23. https://doi.org/10.5204/ssj.1579

This article has been peer reviewed and accepted for publication in Student Success. Please see the Editorial Policies under the 'About' section of the Journal website for further information.

Student Success: A journal exploring the experiences of students in tertiary education

(c) (i) Except where otherwise noted, content in this journal is licensed under a Creative Commons Attribution 4.0 International Licence. As an open access journal, articles are free to use with proper attribution. ISSN: 2205-0795 